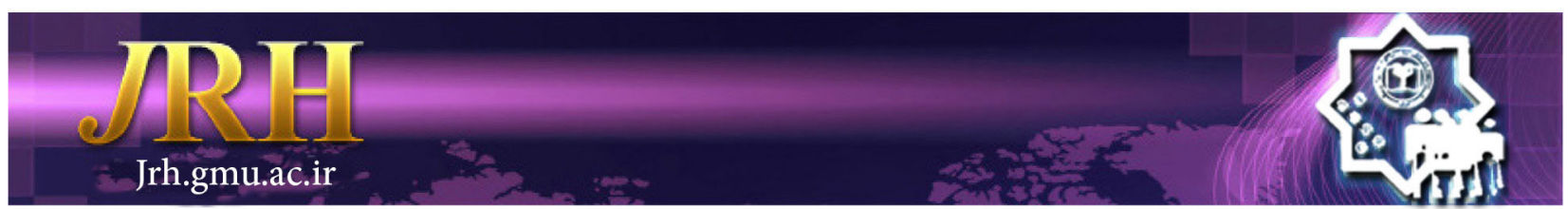

\title{
The effect of sound with different frequencies on men and women noise annoyance
}

Mohammad Hosein Beheshti ${ }^{1}$, Mojtaba Emkani ${ }^{1}$, Maryam Borhani Jebeli $^{2}$, Ali Tajpoor ${ }^{3}$, Ali Firoozi Chahack ${ }^{1}$, Ghasem Yarahmadi ${ }^{4}$, Hamid Piramoon ${ }^{4}$, Sekineh Khoshehsahi ${ }^{4}$, Negar Zobeidi ${ }^{4}$

\author{
Journal of Research \& Health \\ Social Development \& Health Promotion \\ Research Center \\ Vol. 9, No.4, Jul \& Agu 2019 \\ Pages: $355-362$ \\ DOI: $10.29252 / j r h .9 .4 .355$ \\ Original Article
}

1. Department. of Occupational Health, School of Health, Gonabad University of Medical Sciences, Gonabad, Iran

2. Department of Occupational Health, School of Health, Iran University of Medical Sciences, Tehran, Iran

3. Department of Occupational Health, School of Medical Sciences, Tarbiat Modares University, Tehran, Iran

4. Department, of Occupational Health, School of Health; Student Research Committee, Gonabad University of Medical Sciences, Gonabad, Iran

Correspondence to: Ali Firoozi Chahack, Department. of Occupational Health, School of Health, Gonabad University of Medical Sciences, Gonabad, Iran

Email: ali_firoozi66@yahoo.com

Received: 23 Nov 2017

Accepted: 12 Mar 2018

How to cite this article: Beheshti $\mathrm{MH}$, Emkani M, Borhani Jebeli M, Tajpoor A, Firoozi Chahack A, Yarahmadi Gh, Piramoon $\mathrm{H}$, Khoshehsahi S, Zobeidi N. The effect of sound with different frequencies on men and women noise annoyance. $J$ Research \& Health2019; 9(4): 355- 362.

\begin{abstract}
Sound is an effective exogenous factors which affecting human brain processing mechanisms. This research was quasi experimental study that was carried out among 70 students to evaluate the effect of sound frequency on human noise annoyance. Noise annoyance degree was measured during exposure to sound at various frequencies of 500, 1000, 2000, 4000 and $8000 \mathrm{~Hz}$. Sound.exe software was used to determine the sound with different frequencies and noise annoyance was determined based on the acoustic questionnaire "Acoustics Assessment of noise annoyance by means of social and socio-acoustic surveys". According to the results of this study, in female participants, the maximum degree of noise annoyance is at $4000 \mathrm{~Hz}$ and in male subjects, the highest degree of noise annoyance is at $8000 \mathrm{~Hz}$ and from 500 to 8000 $\mathrm{Hz}$, the frequency of noise annoyance increases, respectively. There was significant relationship between noise annoyances with different frequencies. The highest level of noise annoyance was at $8000 \mathrm{~Hz}$ and the lowest level was at 500 . There was significant difference between male and female dissonance. In this study, the gender variable as one of the factors affecting anxiety was studied. The results of this study showed that the frequency with maximum noise annoyance is different in men and women and the maximum degree of noise annoyance is at 4000 and $8000 \mathrm{~Hz}$.
\end{abstract}

Keywords: Frequency, Noise, Sound, noise annoyance

\section{Introduction}

Over the past decades, noise pollution caused by industrialization has become a main concern worldwide because of its adverse effects on human well-being [1]. Noise is unwanted or undesirable sound. Noise can be either occupational or environmental, depending on its source. The Exposure of occupational noise occurs in the workplace and environmental noises are produced from all other nonworkplaces including roads, railways, airports, and even neighborhoods [2-4]. Sound is one of the most effective exogenous factors which affecting the processing mechanisms of the brain including attention and reaction time. Exposure to noise pollution is considered to be an environmental hazard, which plays 
a major role in environmental health [5]. The WHO has accepted environmental noise as harmful pollution that causes adverse psychosocial and physiologic effects (such as, annoyance and sleep disorder) on human health [6]. The significant effect of sound on human health is well-known phenomenon [5]. So that the biologic plausibility for noise stress-related cardiovascular responses is well established [7] an association between noise exposure and sleep quality have found by diverse epidemiological studies, but the mediating role of annoyance is unclear for this association [8]. Mental annoyance caused by noise pollution is a common phenomenon in modern societies, especially in industry [5]. Lindvall has introduced noise annoyance as "a feeling of displeasure associated with any agent or condition (related to sound) that is believed to affect adversely an individual or a group" [9]. Generally, noise annoyance is defined as a negative evaluation of environmental conditions, but its connotations are rather broad and diverse. The concept is accompanied with disturbance, aggravation, dissatisfaction, concern, bother, displeasure, harassment, irritation, nuisance, vexation, exasperation, discomfort, uneasiness, distress and hate. We will not discuss the conceptual and methodological problems of the annoyance concept here; this was previously has done by Guski 1997 [10,11]. Disturbing and unpleasant sound may cause anger and irritability among people. Noise is often discussed for psychological costs. Various studies have indicated that Noise annoyance is dependent on Psychological and physiological characteristics of the individual [5]. Therefore, various studies have investigated the factors affecting noise annoyance. According to the results of the study, even exposure to lowintensity background noise could lead to increased energy consumption and disruption of spatial attention [12].

Sound causes anger and mental disorientation. It does not require sound to be intense but a wall clock tick in a waiting room is enough to affect the sensitive and susceptible people causing their anger and aggression. In industrial environments, no process is carried out with $100 \%$ efficiency and unfortunately part of the desired performance becomes unwanted and unwanted products [13].

A study by Muzet and colleagues in 2007 showed that sound in disrupts mental works more than physical activity and when it is more than $90 \mathrm{~dB}$, it increases energy to maintain a state of consciousness [14]. A study that was carried out in 1968 to examine the various effects of sound on complex tasks found that in exposure to noise increasing the complexity of the work activity, the number of errors increased which reduced the error rate by simplifying these activities [15].

Finally, investigating and studying noise emissions and related annoyance is important from different points of view since noise affects the environment quality, the resident's satisfaction as well as their well-being and health [16].

Various studies have shown that sound can affect the concentration, attention, alertness, accuracy, and stress of individuals. But there are some studies in this field that the effect of sound level has been raised in most studies and sound is considered as a single variable and various audio features including the frequency of sound have not been investigated. In the meantime, Sound frequency is one of the most important factors that have a major effect on noise abnormalities. And the important point is that the change in any of the sound variables such as intensity, pressure, and frequency of sound may result in a change in each of the complications expressed.

On the other hand, various studies have indicated that noise annoyance is dependent on psychological and physiological characteristics of the individual. And the first important feature in demographic variables is Sexual difference between persons exposed to different sound frequencies. There are very few researches in relation to the sound frequency or sound with different frequencies and or there are many contradictions in the results of existing studies, which leads 
to a lack of a logical conclusion [5,17-19]. Therefore the aim of the study is to investigate the effect of sound with different frequencies on noise annoyance by gender.

\section{Method}

This research was quasi experimental study as before and during exposure that in which the effect of different sound frequencies on noise annoyance were studied on men and women. This study was conducted in 2017 on 60 students of Gonabad University of Medical Sciences who were selected by simple random sampling method.

Sample size was determined 70 participants based on the study objectives and based on the formula for calculating the sample size in analytical observational and interventional studies (the following formula), and using the same study [20]. In this study, the sample size was calculated using the study of Ali Mohammadi et al [20]. Accordingly, in this study, the mean before and after the study was 2.6 and 2.15 and the standard deviation before and after was 0.22 and 1.29. The sample size was calculated at 95\% confidence level.

Inclusion and exclusion criteria for this study included: all students who tend to participate in the study and do not have any specific mental and hearing ailments. All were students and their ages were ranged from 18 to 25 years old. Participants aged fewer than 18 or over 25 were excluded from the study. Because there are many interfering factors on human response to sounds of different frequencies so far no study has been done in this regard. In order to remove these factors, university students were selected to conduct the study as a community has more common characteristics than other groups of society.

In this study, participants were included that was similar in sexual, age and physical conditions who were similar in age range and suffering from any diseases and cardiovascular disorders and mental-psychological disorders. In this study, to eliminate interference due to the cumulative effects of sound at different frequencies, participants were tested with only one frequency of sound each day only. A pilot test was carried out before the main measurement, in order to familiarize participants with the test method. Measurements and tests in this study were performed at various frequencies of 500, 1000, 2000, 4000 and $8000 \mathrm{~Hz}$. Sound.exe software was used to determine the sound with different frequencies, The TES 52 A manufacturing facility in Taiwan was used to determine the accuracy and frequency of the sound, after adjusting the sound in terms of intensity and frequency, noise annoyance tests were performed [21]. Because the sound was not tolerated for more than 10 seconds at some frequencies, the exposure time was 10 seconds. Noise annoyance was determined based on the acoustic questionnaire "Acoustics -Assessment of noise annoyance by means of social and socio-acoustic surveys" which is available in the ISO / TS 15666 standard [22]. This scale contains numbers from 0 to 10 , which zero means represents no annoyance and the number 10 also shows excessive annoyance.

If the responses of workers are in the range of $2-0,4-2,6-4,8-6$, or $10-8$, they indicate no annoyance, mild annoyance, moderate annoyance, high annoyance and excessive annoyance.

The data were analyzed by using SPSS-21 and the significant level was less than $5 \%$. Regarding the data was normal, the ANOVA and t-test were used to analyze the data. This study was approved at the University's Ethics Committee and before the study; all participants were justified about the method and the objectives of the study.

\section{Results}

In this study, 70 students of Gonabad University of Medical Sciences, 35 were female and 35 males were selected and studied. The average age of males was 21.12 years with a standard deviation of 0.13 and the mean age of females was 19.91 years with a standard deviation of 0.1 . The results of the measurement of noise annoyance at various frequencies are shown in Table 1. 
Table 1 Results of measurement of noise annoyance at different noise frequencies

\begin{tabular}{lcc}
\hline Frequency & $\begin{array}{c}\text { Standard deviation of noise } \\
\text { annoyance }\end{array}$ & $\begin{array}{c}\text { Mean of noise } \\
\text { annoyance }\end{array}$ \\
\hline No sound & 0 & 0 \\
$500 \mathrm{~Hz}$ & 1.55 & 2.12 \\
1000 & 1.9 & 4 \\
2000 & 1.63 & 4.52 \\
4000 & 2.36 & 5.56 \\
8000 & 2.46 & 5.84 \\
\hline
\end{tabular}

According to the results of this study, the highest degree of noise annoyance is at 4000 and $8000 \mathrm{~Hz}$. The results of the measurement of noise annoyance are shown in Figure 1.

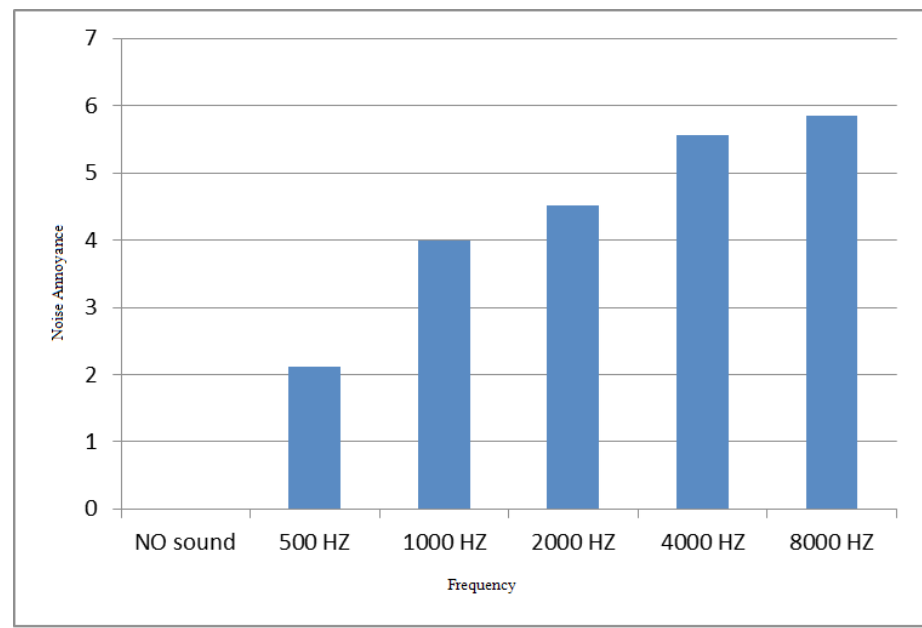

Figure 1 The results of measuring the degree of noise annoyance at different noise frequencies

According to the results of Table 1 and Figure 1 , the increasing in the frequency of sound from 500 to $8000 \mathrm{~Hz}$ lead increases the level of noise annoyance and the highest noise annoyance occurs at 4000 and $8000 \mathrm{~Hz}$. Results of ANOVA test on determining the relationship between sound frequency and noise annoyance showed that there is a significant relationship between noise annoyances with different frequencies $(p<0.0001)$. The results of determining the degree of noise annoyance at different frequencies by female and male are shown in Figure 2.

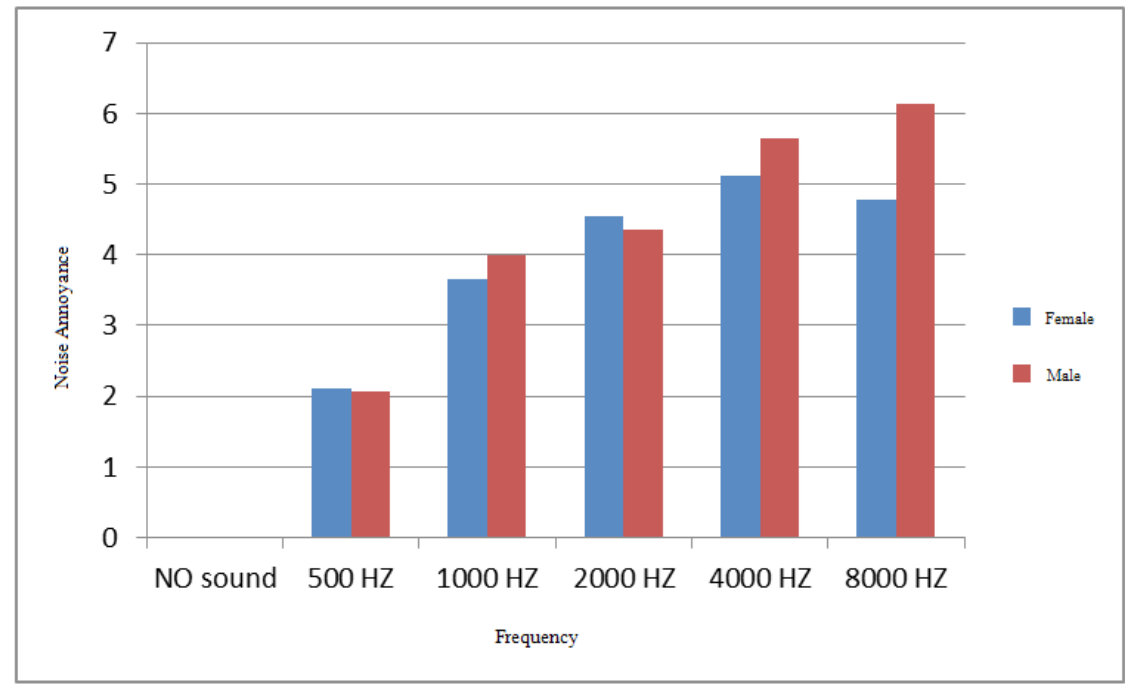

Figure 2 Results of determination of noise annoyance at different frequencies in females and males 
Results of measurement of the degree of noise annoyance at different frequencies in female subjects are shown in Table 2.

According to Figure 2 and Table 2; the maximum degree of noise annoyance in female subjects is at $4000 \mathrm{~Hz}$, and the frequency of previous and subsequent frequencies of $4000 \mathrm{~Hz}$ decreases the degree of noise annoyance. Results of measurement of the degree of noise annoyance at different frequencies in male participants are shown in Table 3.

Table 2 Results of measurement of the degree of noise annoyance at different frequencies in female subjects

\begin{tabular}{lcc}
\hline Frequency & $\begin{array}{c}\text { Standard deviation of } \\
\text { noise annoyance }\end{array}$ & $\begin{array}{c}\text { Mean of noise } \\
\text { annoyance }\end{array}$ \\
\hline No sound & 0 & 0 \\
$500 \mathrm{~Hz}$ & 2.07 & 2.11 \\
1000 & 2 & 3.66 \\
2000 & 1.94 & 4.55 \\
4000 & 2.93 & 5.11 \\
8000 & 3.41 & 4.77 \\
\hline
\end{tabular}

Table 3 Results of measurement of the degree of noise annoyance at different frequencies in male subjects

\begin{tabular}{lcc}
\hline Frequency & $\begin{array}{c}\text { Standard deviation of noise } \\
\text { annoyance }\end{array}$ & $\begin{array}{c}\text { Mean of noise } \\
\text { annoyance }\end{array}$ \\
\hline No sound & 0 & 0 \\
$500 \mathrm{~Hz}$ & 1.22 & 2.06 \\
1000 & 1.92 & 4 \\
2000 & 1.54 & 4.35 \\
4000 & 2.09 & 5.64 \\
8000 & 1.29 & 6.14 \\
\hline
\end{tabular}

According to the results of Table 3 in male subjects the highest degree of noise is at $8000 \mathrm{~Hz}$. And from 500 to 8,000 frequencies, by increasing in the frequency, the noise annoyance increases. The results of the t-test for determining the significance of noise annoyance between males and females showed that there is a significant difference between male and female noise annoyance $(\mathrm{p}<0.05)$.

\section{Discussion}

Noise can cause both physiological and psychological stress. The most investigated potential effects of noise exposure are sleeping disturbance annoyance, cognitive impairment of children, and cardiovascular effects but the evidence on the potential effects on mental health is relatively scarce. In the present study, the results of the measurement of noise annoyance at different frequencies showed that the maximum degree of noise annoyance is at 4000 and $8000 \mathrm{~Hz}$, and with increasing the frequency of sound from 500 to $8000 \mathrm{~Hz}$, the degree of noise annoyance increases and at frequencies of 4000 and $8000 \mathrm{~Hz}$ There is the highest amount of noise annoyance. The results this study showed that there is a significant relationship between noise annoyances with different frequencies. In a study that examined the effects of low- and broadband frequency sound on employees of the control room of the power station and the cement plant found a linear relationship between noise exposure and noise annoyance and stated that the effect of the low frequency sound in noise annoyance is higher than the effect of broadband noise [23]. The World Health Organization (WHO) states that increasing the age causes people to experience hearing loss at high frequencies and this reduces the individual's sensitivity to mid-high frequencies [24]. Therefore, it can be said that older people receive more noise at lower frequencies because of the lowering of the underlying sound effect [24]. 
Based on the comparison of the results of this study with the results of other researches, it seems that in addition to the frequency of sound individual factors such as age and sex as well as physical factors related to sound such as intensity of sound affects amount of noise annoyance at various frequencies. On this basis, under certain conditions, it is possible that the amount of noise in the high frequencies is higher than the low frequencies and in other situations the result may be the opposite. Considering that in the present study, noise annoyance at different frequencies with a sound intensity of $45 \mathrm{~dB}$ was determined. Therefore, it is suggested that in other studies the degree of sound irritation in different age groups and different acoustic intensities should be considered. In most studies in this area, the effect of sound intensity has been raised and few researches have been carried out in relation to the frequency of sound. Most of the studies that have been done in this area are related to low-frequency sound.

Low frequency sound is broadband sound that has a frequency range of 20 to 200 or 10 to 250 $\mathrm{Hz}$ [25]. The main sources of low frequency audio include ventilation systems, pumps, compressors, diesel engines, gas turbines, and so on. The importance of examining the low frequency sound is documentation of WHO is also high [26]. Low frequency sound is less attractive compared to high frequency sounds and the existing laws relating to its control are not satisfactory [27]. In a study that investigated the effect of low frequency voice on mental performance, it was revealed that low-frequency sound reduced mental function [28]. The other study was found that low-frequency sound at moderate levels (50 $\mathrm{dB}$ ) may have a negative impact on focus and attention especially in low-frequency sensitive people [29]. In the study of Iran two types of low frequency and reference sounds have been used in each one with 45 and $65 \mathrm{~dB}$ (A) levels. In this mentioned research, memory and tracking and math tests were used to measure mental performance. The results of this study showed that low-frequency sound with a density of $65 \mathrm{~dB}$ significantly reduced concentration and increased speed compared to low frequency with $45 \mathrm{~dB}$. On the other hand, the reference sound of $65 \mathrm{~dB}$ in comparison with the reference sound of $45 \mathrm{~dB}$ significantly increased the speed [30]. Studies have focused on the importance of human factors (individual characteristics) in causing irritation. One of these is the impact of personal characteristics in dealing with sound [31]. A number of empirical and clinical studies have shown that exposure to noise activates the central nervous system and therefore accelerates the response to some stressors [32]. There is some evidence that the cultural-social differences significantly affect the response to the noise [32]. Given that exposure to sound in people has had different effects, it seems that these differences are related to the personality traits of individuals (introversion-extraversion). Eysenck in his study found that introverts were more intrusive than extrovert people [33]. During this research, there were some limitations and issues that could be mentioned such as the reluctance and willingness of students to participate in the research due to sound irritation. In addition, the paramets and personality traits of individuals such as introverted or outsourced and may be relevant to the results of the research that are proposed to be studied in future studies. In addition, the combination of different intensity and frequencies may have different outcomes it is necessary that this item be considered in subsequent studies.

\section{Conclusion}

The present study showed that the maximum degree of noise annoyance is at 4000 and 8000 $\mathrm{Hz}$. In general, research on sound effects has a vague image on mental performance. One of the reasons for this finding may be due to individual differences in overall sensitivity to sound and sound sensitivity with different frequencies. In addition to sound, there are other environmental factors that may affect cognitive functions. 


\section{Acknowledgments}

This study has been registered as a research project of 483/1/P at the Gonabad University of Medical Sciences. The authors express their gratitude to the Research deputy at Gonabad University of Medical Sciences.

\section{Authors' contributions}

Study design: MHB, ME, AFC

Data collection and analysis: AT, GY, HP, SK, NZ Manuscript preparation: MHB, MBJ

All authors have read and approved the final version

\section{Conflict of Interests}

"The authors declare that they have no competing interests."

\section{Funding}

This study was registered as a research project to number Code No. p/1/551 in the research deputy of Gonabad University of Medical Science.

\section{Availability of data and materials}

The datasets used and/or analyzed during this study are available from the corresponding author on reasonable request.

\section{References}

1- Ongel A, Sezgin F. Assessing the effects of noise abatement measures on health risks: A case study in Istanbul. Environ Impact Assess Rev2016; 56: 180-7.

2- Moudon AV. Real noise from the urban environment: how ambient community noise affects health and what can be done about it. Am J Prev Med2009; 37(2): 167-71.

3- Mehdi MR, Kim M, Seong JC, Arsalan MH. Spatiotemporal patterns of road traffic noise pollution in Karachi, Pakistan. Inviron Int2011; 37(1): 97-104.

4- Ko JH, Chang SI, Kim M, Holt JB, Seong JC. Transportation noise and exposed population of an urban area in the Republic of Korea. Inviron Int2011; 37(2): 328-34.

5- de Castro Rey J de, Gallo J, Loureiro H. Tiredness and sleepiness in bus drivers and road accidents in Peru: a quantitative study. Rev Panam Salud Publica2004; 16(1): $11-8$.

6- Kim M, Chang SI, Seong JC, Holt JB, Park TH, Ko JH, et al. Road traffic noise: annoyance, sleep disturbance, and public health implications. Am J Prev Med2012; 43(4):
353-60.

7- Babisch W, Beule B, Schust M, Kersten N, Ising H. Traffic noise and risk of myocardial infarction. Epidemiology2005; 16(1): 33-40.

8- Frei P, Mohler E, Röösli M. Effect of nocturnal road traffic noise exposure and annoyance on objective and subjective sleep quality. Int J Hyg Inviron Health2014; 217(2-3): 188-95.

9- Lindvall T, Radford EP. Measurement of annoyance due to exposure to environmental factors: The fourth Karolinska institute symposium on environmental health. Environ Res1973; 6(1): 1-36.

10- Guski R. Editor Conceptual methodological, and dose-response problems related to annoyance and disturbance. INTER-NOISE and NOISE-CON Congress and Conference Proceedings; 1997: Institute of Noise Control Engineering.

11- Guski R. Personal and social variables as codeterminants of noise annoyance. Noise Health1999; 1(3): 45-56.

12- Trimmel M, Poelzl G. Impact of background noise on reaction time and brain DC potential changes of VDTbased spatial attention. Ergonomics2006;49(2):202-8.

13- Aliabadi M, Golmohammadi R, Mansoorizadeh M. Objective approach for analysis of noise source characteristics and acoustic conditions in noisy computerized embroidery workrooms. Environ Monit Assess2014; 186(3): 1855-64.

14- Muzet A. Environmental noise, sleep and health. Sieep Med Rev2007; 11(2): 135-42.

15- Kryter KD, Poza F. Autonomic system activity and performance on a psychomotor task in noise. $J$ Acoust Soc Am1980; 67(6): 2096-8.

16- Camusso C, Pronello C. A study of relationships between traffic noise and annoyance for different urban site typologies. Transp Res D Transp Environ2016; 44: 122-33.

17- Stansfeld SA, Matheson MP. Noise pollution: nonauditory effects on health. British Medical Bulletin2003; 68(1): 243-57.

18- Nitschke M, Tucker G, Simon DL, Hansen AL, Pisaniello DL. The link between noise perception and quality of life in South Australia. Noise Health2014; 16(70): 137-42.

19- Gholami T, Piran Veyseh P, Aliabadi M, Farhadian M. Evaluation of noise pollution and its effects on subjective fatigue of staffs in the governmental banks of Hamadan city. Iran Occupation Health2014; 11(5): 65-73.

20- Alimohammadi I, Farshad A, Falahati M, Mousavi B. The effects of road traffic noise on the students' errors in movement time anticipation the role of introversion. Iran Occupation Health2012; 9(3): 52-9.

21- Behnam Shafi H, Nasimi F, Boskabadi H, Ketabi D. 
Noise pollution in neonatal intensive care units in Qhaem hospital. Journal of Mazandaran University of Medical Sciences2014; 24(118): 235-6.

22- Acoustics I. Assessment of noise annoyance by means of social and socio-acoustics surveys. ISO/TS 15666: 2003. 23- Pawlaczyk-Luszczyńska M, Dudarewicz A, Waszkowska M, Śliwińska-Kowalska M. Assessment of annoyance from low frequency and broadband noise. Int $J$ Occup Med Environ Health2003; 16(4): 337-43.

24- Abbasi M, Monazzam Esmaielpour M, Akbarzadeh A, Zakerian SA, Ebrahimi MH. Investigation of the effects of wind turbine noise annoyance on the sleep disturbance among workers of Manjil wind farm. Journal of Health and Safety at Work2015; 5(3): 51-62.

25- Leventhall HG. Low frequency noise and annoyance. Noise Health2004; 6(23): 59-72.

26- Berglund B, Lindvall T, Schwela D. Guidelines for community noise. World Health Organization; 1999.

27- Waye KP, Bengtsson J, Kjellberg A, Benton S. Low frequency noise "pollution" interferes with performance. Noise Health2001; 4(13): 33-49.
28- Bengtsson J, Waye KP, Kjellberg A. Evaluations of effects due to low-frequency noise in a low demanding work situation. J Sound Vib2004; 278(1-2): 83-99.

29- Pawlaczyk-Łuszczyńska M, Dudarewicz A, Waszkowska M, Szymczak W, Śliwińska-Kowalska M. The impact of low frequency noise on human mental performance. International Int J Occup Med Inviron Health2005; 18(2): 185-98.

30- Kazempour M, JafariMJ, Mehrabi Y, Alimohammadi I, Hatami J. The impact of low frequency noise on mental performance during math calculations. Iran Occupation Health2011; 8(2): 47-56.

31- Lercher P. Environmental noise and health: An integrated research perspective. Inviron Int 1996; 22(1): 117-29.

32- Paunović K, Jakovljević B, Belojević G. Predictors of noise annoyance in noisy and quiet urban streets. Sci Total Environ2009; 407(12): 3707-11.

33- Eysenck M. Attention and arousal cognition and performance. Berlin, Germany: Springer Science \& Business Media; 2012.

Copyright $(\mathcal{C} 2016$ ASP Ins. This open-access article is published under the terms of the Creative Commons Attribution-NonCommercial 4.0 International License which permits Share (copy and redistribute the material in any medium or format) and Adapt (remix, transform, and build upon the material) under the Attribution-NonCommercial terms. 